\title{
The Growth of the Journal of the American Society for Mass Spectrometry
}

Y

ou have noticed by now that this issue of JASMS contains approximately twice as many pages as has been customary. The reason is the Journal is attracting more and more papers, and we've fallen behind our publication schedule. We realize that this causes some concern and disappointment for authors who are anxious to see the results of their work "reach the light of day" as soon as possible. For these delays, we apologize!

Journal growth is like that of a child: it occurs slowly, almost imperceptibly, and then one day the backlog of papers is nearly twice what it should be. We, like many of you, noticed the change and we have taken measures to do something about it. This special conference issue is one of those measures.

We are delighted to announce that Elsevier, our Publisher, has agreed to allocate 188 extra pages to Volume 3 without additional cost to the society. This extra page allocation will allow us to publish $75 \%$ of the backlog in 1992 . Approximately $37 \%$ of the backlog is published in this issue, and the remaining $37 \%$ will be evenly distributed over the remaining four 1992 issues.

The current backlog is approximately four months. That means that instead of bringing an accepted paper to press in four months, it currently takes eight months. The obvious solution is to publish more pages to keep up with the paper acceptance rate. That is not so simple, however. Page numbers as well as journal size and frequency are matters that are negotiated by the Society and the Publisher once a year at the time of the annual conference. Changing plans is not trivial given that there is a budget for the journal and that the journal is provided to all members of the Society as a benefit of membership.

A decision will be made at the time of the 1992 conference about publication frequency and journal size in 1993. We will be able to react to continuing growth by increasing the page count or the issue number. Our expectation is that the remaining $25 \%$ backlog and any new backlog that develops in late 1992 will be handled by increased allocations in 1993.

We are particularly grateful to Nick Baker, Associate Publisher, and Paul Weislogel, Publisher, for their special consideration and support of JASMS. We are also grateful to our readers and authors for their patience and understanding. Prospective authors should be assured that the time between acceptance and publication of manuscript should soon return to a normal state. Moreover, the Society membership should be reassured that we remain committed to the goal the JASMS should become the general interest journal in the field of mass spectrometry.

Sincerely

Michael L. Gross

Editor
Robert C. Murphy

President 